\title{
A FAVOR DEL CONOCIMIENTO CIENTÍFICO (LOS NUEVOS MUSEOS)
}

\author{
Jorge WAGENSBERG \\ Director del Museu de la Ciencia de la Fundació "La Caixa"
}

En este artículo se reflexiona sobre algunas de las claves del conocimiento científico, sus modos de producción, el acceso que a este conocimiento tiene el ciudadano, así como sobre el papel de los museos de la ciencia como proveedores de estímulos e interrogantes y como lugares de encuentro entre científicos, organizaciones sociales y ciudadanos.

\section{El concepto museo (dos principios preliminares)}

Cada forma de transmitir conocimiento dispone de un elemento portador que le es propio y de algunos otros que son accesorios. Así, las clases, las conferencias, los debates y los seminarios se basan en la palabra bablada; en el cine, la televisión y otros audiovisuales el portador fundamental de conocimiento es la imagen; para los libros, las revistas y otras publicaciones lo esencial es la palabra escrita, el texto; el juego, que tanto se usa en el reino animal para aprender, cuenta con el recurso de la simulación. ¿Y los museos? Los museos, las exposiciones y las demostraciones se centran, sobre todas las cosas, en el objeto (o suceso) real. Cada una de estas formas de transmisión puede tomar prestados, como auxiliares, otros portadores de conocimiento de las otras formas. Así los conferenciantes apoyan sus palabras con diapositivas (imagenes), los museos explican sus objetos reales con textos que incluso completan con dibujos o fotografías,... Uno de los vicios más ingenuos de la museografía actual consiste, justamente, en olvidar esta prioridad irrenunciable por lo real: exposiciones reducidas a un libro cuyas páginas han 
sido magnificadas y dispuestas en posición vertical y que el sufrido visitante lee paseando por un pasillo; salas de museo repletas de videos y ordenadores, que más parecen tiendas de electrodomésticos, demostraciones sobre maquetas de todo tipo,... Asumir la hipótesis de trabajo de que un museo se basa en sucesos y objetos reales parece anterior a cualquier otra. Lo contrario es sustituir con desventaja: exposiciones que se recorren leyendo de pie, salas repletas de pantallas de ordenador o de viseo, museos que son impensables sin un guia explicador, muestras de efectos especiales,... Asumámos pues la hipótesis. La realidad será, como mínimo, una promesa que nos ayude a salir de casa.

De este primer principio surge, con vigor propio, un segundo principio. Basta un vistazo a la reciente museología científica para apercibirse de ello. En efecto, los centros y museos de ciencia son sin duda los que más han movido sus contenidos, sus métodos, su papel en la sociedad y su actitud frente al ciudadano:

del lema "prohibido tocar" se ha pasado al lema "prohibido no tocar", del concepto vitrina se ha evolucionado a la idea de experimento, de la etiqueta académica se ha derivado hasta el texto de calidad literaria, de contar con el sentido de la vista como única vía de percepción se ha pasado a disponer de la totalidad del sensorium (o casi), el acento ha pasado de la preparación de respuestas a la preparación de preguntas, del amor exclusivo por el pasado se ha pasado a un deseo de utilizar el museo como un útil de cambio, ...

Todo esto se puede resumir en un segundo principio sobre las prioridades museológicas. Aunque nada de lo que sigue está prohibido, la prioridad primera de un museo moderno de ciencia no es tanto conservar un patrimonio, informar, formar o enseñar,... la prioridad primera es proveer estímulos. ¿Por qué estímulos? ¿Qué clase de estímulos? ¿¿e qué manera se presentan en un museo? Combinando estos dos primeros principios podemos aventurar ya una primera conclusión:

Un museo moderno debe favorecer la provisión de estimulos basados en los objetos y fenómenos de la realidad.

Existe sin embargo una cuestión previa. ¿Por qué un museo? ¿Es que no basta con la enseñanza formal, con los medios de comunicación ya consagrados,...? La raíz de esta pregunta, la necesidad del museo y de sus estímulos, está en una gran contradicción de nuestra sociedad actual. La que sigue. 


\section{La gran contradicción (o la necesidad de los estímulos)}

Tras miles de millones de años de evolución biológica la selección natural ha consagrado unas pocas e importantísimas funciones básicas como la alimentación, la respiración o la reproducción. ¿Cómo se las ha arreglado la evolución para que las criaturas de este mundo no se olviden de beber y de comer, de respirar o de dejar copias a tiempo para la continuidad de la especie? La cuestión no es en absoluto trivial. En efecto, como todo el mundo sabe, la materia en general, y la materia viva no es una excepción, es esencialmente perezosa y tiende siempre a las situaciones de mínima energía. Se diría que, en principio, entre hacer y no hacer, mejor no hacer. ¿Por qué abandonar la segura guarida para salir al azaroso exterior y gastar energía en busca de comida o de un posible cónyuge? Si no fuera porque las punzadas del hambre, no comeríamos. Eso es lo que ocurre a medida que la evolución se desenrosca: ciertos fuertes estímulos son seleccionados para garantizar las funciones básicas: Hambre y sed para la alimentación, potente y urgente requerimiento a favor de la respiración, eficaz estímulo sexual para la reproducción. Dicho de otro modo, aquellas criaturas nacidas «inapetentes» en alguno de estos sentidos ... hace ya tiempo que han desaparecido. Esos estímulos, a la vez urgentes y no exentos de ciertas promesas de goce, parecen condición necesaria para la continuidad en la vida. Pues bien, a nosotros, la especie humana, nos ha tocado vivir una auténtica efemérides transhistórica. Resulta que hemos inventado (o quizá sólo consagrado) el conocimiento como una función útil para la sobrevivencia. Gracias al conocimiento hemos conquistado el planeta a una velocidad de vértigo: hace apenas cien mil años que hemos accedido a él. ¿̨Cual es el problema? Pues que la selección natural aún no ha tenido tiempo de trabajar a favor del conocimiento para consolidarlo con algún estímulo a la vez urgente y placentero. Es el centro de la mayor contradicción de la civilización: Nos hemos hecho adictos al conocimiento y la selección no nos ha regalado todavía un estímulo que lo consagre. $\mathrm{Y}$ así nos va... No podemos sentarnos a esperar que la evolución biológica resuelva nuestras contradicciones. Sólo hay una solución: regalarnos a nosotros mismos ciertos estímulos a favor de la sed de conocimiento y a favor de la creación de opinión científica.

Quizás haya exagerado un poco. Basta revisar brevemente la historia de la humanidad para constatar que, curiosamente, las civilizaciones más remotas e independientes entre sí, tienen creencias sobre el más allá, dioses, ritos y toda clase de objetos y representaciones artísticas, y armas, útiles y prácticas proto- 
científicas. Según ciertos autores, en los últimos sesenta mil años han emergido unas cien mil religiones. Maticemos. Existe, sí, cierto fuerte estímulo innato para con el conocimiento de tipo revelado. ¿Cómo sino resulta tan difícil encontrar rastros de un grupo humano que no exhiban un culto a cierta divinidad? Existe, también, un cierto, no tan fuerte, estímulo para con el arte. Esto permite situar la cuestión en su justa medida: Lo que no existe es, sobre todo, un estímulo que favorezca la práctica espontánea del método científico.

Unos pocos individuos producen, a gran velocidad, cantidades ingentes de conocimiento cientifico que paga, sufre y disfruta la humanidad entera. Tal contradicción se agiganta al paso de cada minuto por dos razones. La primera es obvia ¿̨cómo puede influir en su futuro un ciudadano de una sociedad democrática marcada por la ciencia si su formación científica no equivale ni a la que regía durante la Edad Media? Necesita estímulos. La segunda no es tan obvia. El ciudadano moderno suele echar mano, ante cualquier complejidad, de los métodos tipo artístico y tipo divino, para los que sí tiene ciertos estímulos naturales. Su recetario está claramente incompleto. Pensemos por ejemplo en algo tan frecuente, y a la vez tan complejo, como comprender al prójimo (al familiar, al de familia ajena, al de otro barrio, otra ciudad, otra región, otro país, otro continente, otra cultura, otra religión, otra raza, ...) La historia de la infamia humana es la historia de la intolerancia. Y lo que se necesita no es sólo tolerancia sino la genuina aceptación del prójimo. El método científico, que no los científicos, quizá pueda ayudar a ello. Éste método, que insistamos ni siquiera los científicos aplican fuera de su oficio (con frecuencia ni siquiera dentro de él), es el único que cambia la verdad cuando ésta ya no resiste la compatibilidad con la observación del mundo, el único para el que todo es revisable.

Los estímulos cientificos son pues doblemente necesarios: a) para la ciencia misma y b) para todo aquello que, aún no científico, pueda beneficiarse del método científico. Con esto estamos aún más cerca del centro de la cuestión. Un museo que acepta la provisión de estímulos al ciudadano como primera prioridad, centra su tarea en crear una diferencia entre el antes y el después de la visita. Es muy posible que una visita no de para mucho más. Pero esa diferencia debe servir para todo lo demás, para promocionar la lectura, las clases, la formación, la información, la valoración y protección de toda clase de patrimonios,... y tantas otras experiencias a favor del conocimiento científico. ¿Qué es el conocimiento científico? 


\section{Crear conocimiento científico (o la necesidad del método)}

Existen métodos para crear conocimiento y métodos para transmitir conocimiento. A lo mejor, y en ausencia de más información, resulta que el mejor método para transmitir un cierto conocimiento es el mismo que se ha utilizado para crearlo. Es muy posible incluso que la idea de pedagogía, entendida como un conjunto de técnicas destinadas a transmitir cualquier tipo de conocimiento, sencillamente no tenga sentido. Esta consideración se puede aplicar a la idea de museo de la ciencia. En efecto, el museo está para transmitir ciencia y resulta que su contenido, la ciencia, tiene un método concreto de cierta solera.

El método. El conocimiento es una representación (necesa-riamente finita) de un pedazo de la realidad (presuntamente infinita). La ciencia es conocimiento elaborado con el método científico. $\mathrm{Y}$ método científico es cualquier método que respete tres principios: el de objetividad, el de inteligibilidad y el dialéctico. Se es objetivo cuando, ante varias formas de observar un objeto, se opta por aquella que menos afecta a la observación. Se es inteligible cuando la representación es, en algún sentido, más compacta que lo representado. Y se es dialéctico cuando el conocimiento se arriesga a ser derribado por la experiencia. El conocimiento es científico cuando tiene voluntad de serlo, es decir, cuando logra la máxima objetividad, inteligibilidad y dialéctica ... por exiguos que sean tales máximos. Según esto, tan científico puede ser un mecánico de carambolas de billar como un físico cuántico. Según esto, un psicólogo no tiene por qué ser menos científico que un físico ... (otra cosa es que se renuncie explícitamente). De la misma manera, nada hay en contra de que la política, una forma de conocimiento dedicada a organizar la convivencia, se construya con método científico ... (otra cosa es que se haya intentado muy poco). Hay tantas formas de conocimiento como métodos para elaborar representaciones de la realidad. Sin embargo, es muy posible que todas ellas sean combinaciones de sólo tres. En efecto, además del conocimiento científico, se puede decir que hay otras dos formas: el conocimiento artístico y el conocimiento revelado. El conocimiento artístico no requiere necesariamente la objetividad ni la inteligibilidad. Se basa, simplemente, en un asombroso y único principio: ciertas complejidades infinitas, no necesariamente inteligibles, son transmisibles a través de una representación finita (una partitura, un cuadro, una mueca). El conocimiento revelado, por su parte, se basa en dos eficaces principios: a) Existe un ente propietario del conocimiento de toda la realidad y b) Tal 
ente tiene a bien revelarnos (a veces) (parte) de su conocimiento. (Es la religión, esa rara inspiración, la superstición, ...).

El conocimiento cientifico requiere pues un método. Existe, sin embargo, una cuestión previa. ¿¿Por qué hace ciencia el científico? ¿Cuál es su necesidad, si la hay? ¿Cuál es su estímulo? Este punto será, como veremos, esencial a la hora de volver sobre el tema de la transmitibilidad de conocimiento.

El estímulo. ¿Qué es lo que mueve a un cientifico a investigar? No creo que haya que buscar razones éticas a esta pregunta. El cientifico no persigue ni el bien ni el mal de la humanidad. Es bastante más sencillo. El cientifico, como cualquier ciudadano, necesita producir conocimiento sobre el mundo para poder compartir al máximo su soledad cósmica. La ciencia se distingue de otras formas de conocimiento solamente por el método empleado para producir tal conocimiento: el método cientifico. ¿Hay algo en ese método que estimule la labor del investigador? El método cientifico tiene un protagonista: el experimento. Experimentar es un intento de diálogo con la naturaleza. No todas las preguntas son buenas, ni siquiera suele estar claro que deba hacerse pregunta alguna. Por ello no siempre hay respuesta $o$, al menos, no siempre hay una respuesta que sirva para producir conocimiento. Pero cuando la hay, cuando la naturaleza, de repente, responde con algo inteligible, entonces es la hora de la verdad del cientifico. Es el momento en el que se consuma la comunicación hombre-naturaleza, es la emoción del cientifico, comprable, por otro lado, con el momento de la emoción en arte, es decir, cuando el creador de una obra se comunica con cierto contemplador a través de una obra. Estímulo y emoción son las palabras claves para el punto cero de todo conocimiento, para arrancar con su creación o con su transmisión. Son estímulos y emociones que resultan de experimentar el mundo.

\section{Transmitir conocimiento científico (en un museo de ciencia)}

Reagrupemos fuerzas: a) El conocimiento es un logro de la evolución biológica, pero es transmisible por vía no genética, b) El conocimiento se crea a partir de unos estímulos, y c) El conocimiento se elabora mediante un método. En particular, el conocimiento científico es el elaborado con el método científico.

¿Cómo elegir los estímulos? ¿La diversión? ¿El juego? ¿El beneficio del resultado? ¿Alguna clase de premio? ¿El miedo a un castigo o a alguna conse- 
cuencia negativa? Hay, en efecto, muchas clases de estímulos, pero en ausencia de otra información ¿por qué no probar con los estímulos que hacen que el científico haga ciencia? En otras palabras, los estímulos del científico ya han servido para algo: para hacer ciencia. A lo mejor también sirven para transmitirla. Aquí tenemos una propuesta de hipótesis de trabajo:

a) Los estímulos que favorecen la creación de un conocimiento son los mismos que favorecen su transmisión

Para transmitir estímulos cientificos, mejor sentirlos primero. Y lo mismo se puede decir, creo, del arte o de cualquier tipo de mística.

Segunda cuestión. Ya hemos conseguido transmitir los estímulos y el destinatario ya tiene sed de ciencia. ¿Con qué método transmitimos el conocimiento? ¿Cómo lo hacemos inteligible? He aquí la segunda hipótesis fundamental:

b) El método que favorece la transmisión de un conocimiento es el mismo que ha favorecido su creación

En pocas palabras, buscar estímulos en la propia ciencia y mostrarlos objetiva, inteligible y dialécticamente, es, como mínimo, algo a probar. Ya tenemos método museológico para utilizar en la elaboración de cualquier oferta en un museo moderno de ciencia. Simplemente, todo método que respete las dos principios enunciados. El conjunto de estas dos hipótesis de trabajo equivale a todo un talante para la transmisión de conocimiento. Se podría expresar más o menos asi:

La idea fundamental para la transmisión de conocimiento consiste en la tendencia a poner al destinatario de la transmisión literalmente en la piel de quien lo ha elaborado.

En la jerga de los museólogos de ciencia y, por extensión, en la de toda clase de museólogos, ha surgido un término para consagrar el método: la interactividad. Es la manera de que el ciudadano viva las emociones del científico. La proximidad entre museólogos y científicos profesionales (investigadores en 
activo) es por lo tanto altamente recomendable. Obsérvese, de momento, que teniendo presente las hipótesis propuestas, es muy difícil equivocarse y confundirse con la naturaleza del espectáculo que conviene ofrecer en un museo de la ciencia. El propósito ahora es bucear en las emociones de un científico y tratar de precisar un poco más.

\section{El método de la interactividad emocional (Exposiciones)}

Después de treinta años de historia en museos de ciencia, creo que hemos recorrido lo suficiente para afirmar que la implicación del visitante en un museo tiene, como mínimo, tres aspectos diferentes. Contando con una buena combinación de estos tres componentes, a determinar según sea la naturaleza del objeto o el suceso real a transmitir, se define, lo que bien podríamos llamar el método de la interactividad total. Son los siguientes:

1) La interactividad manual (Hands on en la jerga museológica). La primera clase de emoción científica se basa en el experimento. El visitante es un elemento activo de la exposición, usa sus manos para provocar a la naturaleza y contempla con emoción de qué manera ésta responde. Este tipo de interactividad, más concretamente llamada Hands on, se ha convertido en pocos años en la obsesión de todos los guionistas museográficos. La idea del Hands on ha recorrido ya muchas etapas. Su principio o la revolución; su consagración o su esplendor; su consolidación pero también su aplicación viciosa o degeneración. La interactividad manual tiene su mínimo en el semiengaño del simplemente poner en marcha (un pulsador que inicia un espectáculo por lo demás totalmente pasivo). Y culmina cuando el ciudadano puede usar la respuesta de su acción para iniciar una nueva acción, cuando el visitante hace realmente preguntas y cuando es la naturaleza, sin intermediarios, la que responde. El aspecto vicioso de la interactividad manual es cuando lo único que se busca es que el visitante, simplemente, haga algo. Aunque ese algo sea lo que sea. Por ejemplo, accionar un pulsador para iluminar un objeto que, por defecto, estaría a oscuras. Y es que la interactividad manual puede no ser mucho sin cierta dosis de interactividad mental.

2) Interactividad mental (digamos aqui Minds on). La mente del visitante experimenta un claro cambio entre el antes y el después. La mente se tropieza con algún reto que le da trabajo. Por ejemplo sentir el deseo de plantear una, o varias, nuevas cuestiones. Salir de una exposición con más preguntas 
(incluso con más dudas) de las que se tenían al entrar es, justamente, una buena medida del valor de una exposición. Tener algo que resolver, dar con una nueva analogía, detectar una paradoja o una contradicción, vislumbrar una nueva idea, sufrir el asalto de una nueva sospecha, registrar un nuevo dato, planear una nueva experiencia ... todo eso desencadena una actividad entre la mente y la realidad. Pero no hay buena interactividad mental sin una cierta dosis de interactividad emocional.

3) Interactividad emocional (digamos ahora Heart on). En una exposición, los intervalos de tiempo disponibles para centrar la atención de un visitantes son pequeños. Para que el ánimo o el humor del visitante reciba algún tipo de descarga emocional se necesita abordar su aspecto más genuinamente cultural. El objeto o el suceso expositivo puede mostrar matices estéticos, éticos, morales, históricos o simplemente de su vida de cada día, que conecten con algún aspecto sensible del visitante ... Es cuando el uso del arte se hace legítimo para comunicar ciencia. Es lo que hace que, en el fondo, todos los museos puedan ser distintos.

Todo buen estímulo museográfico se basa en una buena receta de estos tres ingredientes. En rigor, los tres tipos de interactividad son emocionales, por lo que yo llamaria interactividad emocional (en el sentido amplio) a la desrita interactividad total. Veamos un par de ejemplos extraídos de una sala del Museu de la Ciència de la Fundació "la Caixa» en Barcelona. Se trata de a) La quietud invisible o el arte de desaparecer y de b) Brevtsima historia de tres rocas nacidas de diferentes.

La quietud invisible o el arte de desaparecer. El visitante se acerca a un gran terrario atraído quizás por el título. Y lo primero que ve es nada. Porque en el interior, decorado con materiales naturales (hojarasca, tierra, raíces, corriente de agua, etc.), viven nada menos que dos o tres docenas de insectos palo. La primera emoción del visitante es, en todo caso, que no parece haber emoción. Su mirada recorre irónica y apresuradamente el pequeño espacio. ¡Otro módulo del museo en reparación! El visitante mira pero no ve ... hasta que algunas se tropiezan con el aviso Aqui hay 30 grandes insectos ¿Cómo pueden no verse treinta insectos en un espacio tan pequeño? La incredulidad del visitante aumenta, pero su concentración aumenta, ... Y de repente jzas! Ve uno claramente, dos, tres, ... ipero si está lleno! Sus ojos los miraban, pero su cerebro no los vela. Es la interacción emocional. La mayor parte de los visitantes que- 
dan literalmente cazados para la percepción de todo lo que sigue. Adjunto al terrario hay una ventana por la que se percibe una nube de puntos aleatoriamente distribuidos en un plano. Imposible reconocer el menor sentido en su disposición. Sin embargo, si el visitante acciona un mando, parte de los puntos se mueven con lo que el dibujo de un animal aparece nítidamente. La interactividad manual es genuina: con la acción el animal se hace visible "aunque ya estaba allí», pero, al cesar ésta, el animal "aún estando allí», desaparece bajo las mismas narices del visitante. El fenómeno estimula la imaginación. Es el concepto genérico del tancredo. Muchos presuntas presas adoptan la estrategia de la inmovilidad rigurosa aunque el aliento del depredador sea ya de una proximidad terrorífica. Además, se conecta con la vida cotidiana ¿Por qué agitamos la mano cuando queremos llamar la atención de un camarero especializado en hacer la vista gorda a todo aquello que se aparta de su línea frontal de visión? ¡Analogía! Se reinterpretan, se releen muchas otras experiencias anteriores. Es la interactividad mental

Brevisima historia de tres rocas nacidas diferentes. El visitante se encuentra, antes de entrar al museo, tres magníficas columnas basálticas hexagonales a modo de monumento escultórico-totémico. Si como es normal, hay cola ante las taquillas, son muchos los ciudadanos que se acercan a curiosear. Una enigmática placa dice: Rocas liquidas: Columnas basalticas de Castellfullit de la Roca. Ver experimento en la Sala $E l$ planeta vivo. Hay una alta probabilidad de que la interacción emocional se dispare en la sensibilidad artística de muchos vecinos. Y no sólo artística. Hay aquí también cierta probabilidad de tocar el orgullo nacional, una probabilidad seguramente proporcional a la distancia que media entre la zona que frecuenta el visitante y el bellísimo pueblo, próximo a Barcelona, de donde proceden las rocas. Arrancamos pues con un toque de interactividad emocional. Una vez en la sala anunciada, el visitante se encuentra con un triple experimento, presidido por tres rocas auténticas y distintas: 1) Un pedazo de columna basáltica hexagonal, 2) una roca sedimentaria cortada limpiamente para mostrar el gradiente, de menor a mayor, del tamaño del grano y una roca volcánica, igualmente cortada, 3) para mostrar en este caso el ordenamiento, de menor a mayor, de los poros. Cada una de las tres rocas preside un experimento que el visitante puede provocar, es la interactividad manual: 1) una carrera de partículas de distintos tamaños en un medio viscoso para 
ver que se ordenan ¡como los granos de la roca sedimentaria!, 2) una carrera de burbujas de aire en un líquido para ver que jse disponen como los poros de una bomba volcánica! Y 3) una espectacular convección de Raileigh-Bénard para ver que las partículas se disponen según una estructura de panal de abejas ¡como las columnas de basalto en una de las cuales, sin darse cuenta en un principio, ha apoyado los codos para observar mejor! Y la interactividad mental es imparable. Los tres ejemplos son tres explicaciones de tres objetos, pero explicados por la propia naturaleza y a requerimiento del visitante. Un objeto es un resultado objetivo, inteligible y dialéctico de un proceso. Los mecanismos analógicos también se ponen en marcha. ¿Cuantas disciplinas científicas se dedican a reconstruir la historia? La geología es una de ellas. Pero son muchas más las ciencias que se centran en el estudio de restos y rastros: la paleontología, la paleoantropología, la arqueología, la cosmología, la propia historia, la investigación polićaca, ...

La necesidad de crear estímulos a favor del conocimiento científico, como objetivo, y la interactividad emocional, como método, permiten ya pensar en proyectar y construir un buen museo de ciencia. Ya tenemos exposiciones permanentes y temporales y, por lo tanto, según haya resultado nuestro trabajo, también tendremos un cierto prestigio, una cierta atmósfera y una cierta credibilidad. Si todo eso alcanza cierto nivel, entonces es hora de pensar en el museo de ciencia como institución ciudadana. Por ejemplo ¿Puede el museo cumplir con alguna otra función? ¿Cual es su papel en una sociedad democrática moderna? El museo sirve, por lo pronto para ayudar al ciudadano a crear opinión científica. Un suceso ocurrido en el Museu de la Ciència hace unos años, nos convenció de esta idoneidad.

\section{La creación de opinión científica (En un museo de ciencia)}

Barcelona, martes, 21 de abril de 1992, 19 horas. Sala del auditorio principal. Dentro del ciclo Las Noches del Museo hoy vienen tres importantes cientificos del CSIC (Consejo Superior de Investigaciones Científicas) para debatir con la audiencia sobre el tema: El Mediterráneo aún no ha muerto. Comparece un químico ambiental, director de un centro de investigación, un oceanógrafo, también director de un centro de estudios avanzadas, y un bió- 
logo investigador del Instituto de Ciencias del Mar. Se trata, en una palabra, de la ciencia oficial. La sala con aforo para 200 personas está llena a rebosar, igual que otras auxiliar de 150 desde donde se puede seguir la sesión por un circuito cerrado de televisión. La espectación por la velada es espléndida. A mí me toca hacer las presentaciones y moderar el debate. Uno tras otro los científicos exhiben datos y exponen sus argumentos ayudándose con lujo de datos frescos, límpidos gráficos y atractivas fotografías. Un cierto optimismo se propaga por la sala. Se define por ejemplo una medida de la tasa de renovación de las aguas del mediterráneo. Al parecer desde que una molécula de agua entra por el estrecho de Gibraltar desde el océano Atlántico, hasta que vuelve a salir, media un tiempo de cien ańos. Este es el dato. Y la interpretación de los científicos: el mar mediterráneo es muy grande, en uchos sentidos es como si fuera un océano. Otro ejemplo: se dan las toneladas de crudo perdidas en el mar por diferentes causas. Ese es el dato. Y la interpretación oficial: eso es muy poca cosa. Hay bacterias apropiadas que darán, sin problemas, buena cuenta de ello. Y otro más: las construcciones para la prospección de petróleo no suponen ninguna tensión suplementaria a la flora y la fauna de las profundidades. Más bien al contrario: suponen protecciones artificiales que favoreceran el florecimiento de nuevos paraisos subacuáticos. El mediterráneo no sólo no ha muerto todavía, sino que no parece nada fácil acabar con él. Todos parecen estar de acuerdo entre sí, los científicos y la audiencia. El acto difícilmente acabará en debate. Los asistentes, en efecto, se miran los unos a los otros agradablemente sorprendidos. Pero el moderador, a pesar de su natural carácter entre ingenuo y semieufórico, escruta la audiencia un poco mosqueado. Algo huele a gato encerrado. Está claro que la sala está entregada de antemano; son de la esfera social y cultural de los ponentes: colaboradores, alumnos, familiares, ... ¡Salvo la última fila! Algo se agita en la última fila. El moderador reconoce a uno de ellos: nada menos que el presidente de Green Peace en España. Esto está mucho mejor. De repente el moderador parece recordar, echa una ojeada al programa que tiene delante y ... jrecuerda! Para el día siguiente, día 22 de abril, y por puro capricho del azar, la celebérrima ONG había alquilado el mismo auditorio para un acto muy similar. El título se parecía mucho al del acto de aquel día, aunque tenía, sin llegar a ser contradictorio, otros matices: $\boldsymbol{E l}$ Mediterráneo se muere. La casualidad era notable porque, aunque la sesión era privada, también me hablan pedido actuar de moderador. La cosa esta clara: los onegetistas se han enterado de la sesión que precede a la suya y se han presentado para tomar medidas y para presentar batalla. Para eso están. El mode- 
rador se frota las manos. Cuando eso ocurre se escucha una gran ovación y el moderador empieza a dar las primeras palabras a la sala. Son intervenciones de la misma onda que las ponencias, una precisión aquí, un piropo por allá, un pronóstico, una confirmación, ... El moderador mira hacia la última fila con impaciencia creciente. ¿¿s que no van a decir nada? Al final se dirige hacia ellos con las cejas levantadas y las manos abiertas como diciendo jadelante, está claro que no compartís lo que se ha dicho, os doy la oportunidad abora ...! Pero los activistas de la ecología ponen los ojos en blanco y se encogen de hombros rechazando la invitación, como diciendo ;Estos no tienen remedio, es el discurso de siempre, inútil intentar nada ...! Antes de despedirme de la audiencia, anuncio el debate del día siguiente e invito a la audiencia a presenciar lo que puede ser la otra cara de la moneda. Identifico a los espectadores de la última fila y la gente se vuelve con curiosidad para mirarlos. A los científicos, después de agradecerles su colaboración, les explico lo sucedido (los científicos se sorprenden de mi sorpresa: ¿Qué esperabas?) y les emplazo para el día siguiente. Incluso les invito (al restaurante que ellos elijan) si acceden a volver, como público, e iniciar ¡ellos! el debate tras las ponencias de los ecologistas. Prometen hacerlo entre risas y pronósticos para el día siguiente.

Barcelona, martes, 22 de abril de 1992, 19 horas. Sala del auditorio principal. Dentro del ciclo Las Noches del Museo, el mismo moderador se sienta para debatir el mismo tema que la víspera. Sólo han cambiado los ponentes ... iy la audiencia! Ni un solo espectador de la víspera ha vuelto. Las dos salas están también repletas. Pero se trata de simpatizantes, curiosos e incondicionales de Green Peace. Después de proyectar unas acrobacias temerarias de miembros de esta ONG, que la audiencia aplaude a rabiar, empiezan las ponencias sobre el mediterráneo. $\mathrm{Y}$ empiezan igual que las del día anterior. Los mismos datos. El tiempo de residencia de una molécula en el mediterráneo es de cien años. De acuerdo en eso. Pero eso significa hoy que el mediterráneo no sólo no es un océano ¡Es un charco! El mismo dato, pero diferente interpretación. También hay acuerdo respecto al volumen de las pérdidas de petróleo en el mar, pero desacuerdo respecto de lo que esa cifra significa. ¿Bacterias que digieren el petróleo? Quizás en el Golfo Pérsico, pero no en la Costa Brava o en la Costa Azul. ¿Paraísos bajo las plataformas? ¡Un sarcasmo!...

... huelga decir que estas dos sesiones sugirieron una idea: la de una tercera sesión abierta a las dos corrientes y atodas las audiencias. Así se hizo algunos meses después. $Y$ hubo debate. Y hubo matices. Porque la esencia, como 
bien se sabe, es una cuestión de matices. Pero la trascendencia de este lance ha sido, pretendemos que sea, de mucho mayor alcance.

La anécdota ha dividido la historia de las actividades del museo en dos partes, un antes y un después, ilustra toda un vicio de nuestra sociedad actual y es la base de toda una propuesta. El análisis no es difícil de hacer:

1) Tenemos un problema. Las cuestiones científicas no afectan sólo a la comunidad científica. En una sociedad democrática todo el mundo debe tener la posibilidad de participar en la toma de decisiones. Y cada día ocurre más que una decisión cualquiera requiere conocimiento científico previo. El conocimiento científico es sobre todo de los científicos, pero la opinión científica debe ser, por igual, de cualquier ciudadano. ¿Donde hacer ciencia para ciudadanos? El museo, como institución a la vez científica y ciudadana parece un buen lugar.

2) Los mismos datos científicos -objetivos, inteligibles y dialécticos- admiten interpretaciones distintas, incluso contradictorias. Luego no basta con transmitir los resultados de la ciencia, quizá convenga transmitir también el método empleado en obtener aquellos, quizá convenga trabajar expresa y especialmente a favor de la creación de opinión científica, la del científico y la de cualquier otro ciudadano. Y todo ello está en la vocación de un museo de ciencia.

3) El científico es, en particular, un ciudadano como cualquier otro, con su (legítima) ideología, sus áreas de simpatizantes «a priori», con su derecho a equivocarse y su con su deber a generar opinión científica. Luego, en una primera fase, conviene incluso estimular la discusión entre científicos (lo que al parecer no ocurre lo bastante de forma espontánea). Y luego conviene también provocar la discusión en un ambiente más promiscuo de pensadores y de tendencias distintas. El museo es el espacio idóneo para ambas cosas. A lo mejor es casi el único. En efecto, las universidades, institutos de investigación son ambientes donde cualquiera, excepto los científicos, se sienten cohibidos. Espacios ligados a ideologías previas (por muy legítimas que éstas sean) desperatarán las suspicacias de los científicos. Se puede conseguir en cambio, con prestigio y credibilidad ganada a pulso, que todo el mundo acepte el museo como un buen escenario.

Conclusión, un museo moderno de ciencia tiene, como mínimo, dos tipos de oferta que ofrecer: 1) Exposiciones permanentes y temporales sobre, en principio, la totalidad de la realidad (desde el Quark a Shakespeare) y 2) En el 
marco de lo conseguido con las anteriores, un intenso programa de actividades destinadas a favorecer directamente la opinión cientifica: cursos, conferencias, seminarios, cursos, congresos, debates, ... En particular el museo debe convertirse, poco a poco, en el escenario natrural de una serie de eventos. Por ejemplo, todo cientifico que pase por la ciudad por alguna razón (en general visitar a un colega o asistir a una reunión científica) que se sospeche tenga algo de interés que decir a la comunidad, debe acabar hablando en el museo. En una ciudad como Barcelona un museo puede conectar a una docena de premios Nobel, cada año, con el ciudadano. La actividad que genera un museo, recogida por los medios de comunicación multiplica la vida científica de una ciudad.

Es fácil concluir que toda ciudad, por encima de cierta masa crítica, debería reivindicar un museo de ciencia, de la misma manera que reivindica una orquesta de cámara o de una orquesta sinfónica. Esto plantea una última cuestión. ¿Cual ha de ser el papel de un museo de ciencia en la sociedad moderna?

7. El papel de un museo de la ciencia (En la sociedad del siglo XXI)

La ciudadanía, el conjunto de los ciudadanos, se divide, respecto del conocimiento cientifico, en cuatro grandes sectores:

1) El sector en el cual el conocimiento científico se crea. Son las universidades, los institutos de investigaciñón, los laboratorios, ... Es la comunidad cientifica.

2) El sector en el cual el conocimiento científico se aplica. Es la industria, son los servicios, lo agropecuario ... Es el sector productivo

3) El sector que gestiona los dos anteriores, es decir la creación y la aplicación del conocimiento científico. Son las autoridades académicas, los dirigentes políticos, ... Es la administración.

4) El sector que sufre y se beneficia de los logros de la creacióny aplicación del conocimiento científico. Es el propio conjunto de todos los ciudadanos, ... Es la sociedad entera.

El lugar que debe ocupar un museo moderno de ciencia está claro en este contexto: ha de ser, sencillamente, el escenario natural común para los actores de estos cuatro sectores. 
Y ha llegado la hora de soñar. Imaginemos que sí, que los museos de ciencia son así algún día, por ejemplo en Europa. O en el mundo. Lo que tendremos en realidad es una red de centros dedicados al conocimiento científico para el ciudadano; todos sobre ciencia, sobre sus resultados, sus métodos, todos compartiendo debates sobre todo aquello de los resultados y los métodos que puede afectar al ciudadano. Todos los museos serán diferentes, porque los museos los hacen los hombres y las mujeres y los hombres y las mujeres son siempre diferentes. Cambiará la sensibilidad estética y artística, cambiarán muchos aspectos culturales, cambiarán las creencias, pero, sin son museos de la ciencia (y además conectados entre sí), todos ellos tendrán, por definición y por método, muchas cosas en común. $Y$ tener cosas en común es algo que ayuda a vivir, a convivir y a tolerar al prójimo. Soñar con una red de museos de ciencia para el siglo que viene es soñar con una red de una nueva clase de catedrales, con una red de aire fresco.

\section{Referencias Biblográficas}

1 Jorge WAGensBerg Ideas sobre la complejidad del Mundo. Serie Metatemas, 9. Tusquets eds. Barcelona, 1994.

2. Jorge Wagensberg Public Understanding in a Science Center, Public Understand. Sci, (1), 31-35, 1992. 